\title{
DIMENSIONAL CHANGES IN DENTAL STONE AND PLASTER
}

\author{
W. T. SWEEN.EY, A.B.,* AND DUANE F. TAYLOR, M.S. $†$ \\ School of Dentistry, University of Michigan, Ann Arbor, Mich.
}

\section{INTRODUCTION}

$\mathrm{T}$ HIS report presents a method of determining the dimensional changes in gypsum dental products, which avoids the disadvantages of previous methods and which provides extreme sensitivity.

As part of the program of research on the gypsum products used in dentistry, a preliminary study was made of various physical properties. This study, which included strength, thermal expansion, setting expansion, and other related properties, soon made it apparent that very little was known about dimensional changes occurring in these products when they are subjected to the technies used in prosthetic dentistry. Inasmuch as the final accuracy of a restoration is controlled to a large extent by these changes in the investing materials, a program was set up to determine the dimensional changes which occur when plaster and stone are subjected to the conditions found in dental practice.

PREVIOUS METHODS FOR DETERMINING DIMENSIONAL CHANGE

The methods which have been used by previous investigators, such as Coleman, ${ }^{1}$ Taylor, Paffenbarger, and Sweeney, ${ }^{2}$ Worner, ${ }^{3}$ Docking and Donnison, ${ }^{4}$ and others, to observe the dimensional changes of gypsum materials used in dentistry have been directed more toward obtaining reliable data on the physical change in linear dimensions of dental plaster, stone, and investments during the setting process than the changes caused by the processing of restorations. The determination of the thermal expansion of casting investments has been the subject of numerous investigations. The equipment used most extensively for thermal expansion determination of dental materials is the fused-quartz tube apparatus ${ }^{5}$ which was developed to measure the thermal expansion of solids.

The methods used to observe length changes of gypsum after it has set have been rather crude and are not adaptable to observing the effect of various conditioning and processing technies. Basically, three methods have been used to measure these changes, with each having its characteristic disadvantage. Those methods that depend on a micrometer coming in contact with the surface of a plaster or stone sample are subject to error on repeated measurements because of the ease with which the surface is abraded or worn away. The methods which use index lines and a comparator microscope present practical difficulties in alignment and in getting suitable lines on the sample. ${ }^{3}$ Methods for observing length changes by using a dial gauge in contact with a single specimen, which is not removed, restrict the number of specimens that can be measured conveniently. Also, it is sometimes desirable to maintain specimens under storage conditions which are impractical with the dial gauges.

The project was sponsored by Office of Naval Research, Contract N6-onr.-232, Task Order VIII.

Received for publication, June 20, 1950.

* Present address: National Bureau of Standards, Washington, D. C.

$\uparrow$ Present address: Washington University, St. Louis, Mo. 
The necessity of developing a more suitable method for measuring plaster and stone specimens when subjected to conditions simulating those used in dentistry led, after several attempts, to the method to be described.

\section{PROPOSED METHOD OF MEASUREMENT}

A method was developed which made use of the surface of three embedded metal spheres to determine a reference plane at one end of the specimen, and the surface of a single embedded sphere to determine a point on the other end. This practice avoids dimensional change due to wear in measurement and handling.

The change in length of the specimen is determined by observing the difference in dimensions developed between the reference plane and the point. This can be done by any one of several length measuring technics. It has been found that by comparing the length of the specimen with gauge blocks, by use of an Electrolimit Comparator (Pratt and Whitney, Hartford, Conn.), it is possible to make rapid measurements accurate to the order of 0.0001 inch or better. A sensitive dial gauge might also be used, but would require more care to achieve the same precision.

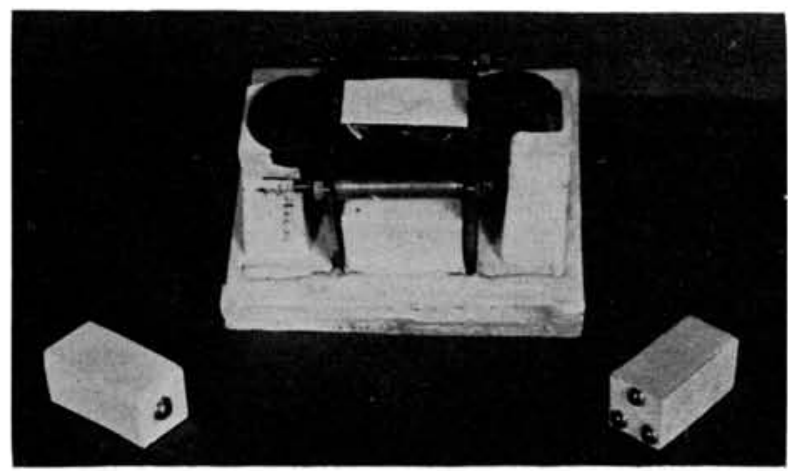

Fig. 1.-Mold for casting gypsum specimens.

The following is an outline of the method used in making observations on gypsum materials such as dental plaster and stone:

1. A form, which consisted of plastic elastomer sides (V-B-M) and metal ends, to mold the specimen $\left(1^{\prime \prime} \times 1^{\prime \prime} \times 21 / 2^{\prime \prime}\right)$ was prepared. The ends had countersunk holes into which were placed stainless steel balls. At one end the holes were spaced to form an equilateral triangle, at the other a single hole was centered. The metal plates were brass and the stainless ball bearings were held in the countersunk holes by means of permanent magnets (Fig. 1).

2. The gypsum to be measured was mixed and poured into the assembled mold to harden or set.

3. The mold is then disassembled after the gypsum has hardened and the specimen is removed.

4. The initial length of the specimen should be determined in the Electrolimit Standard External Comparator by placing the specimen in the comparator 
and adjusting the instrument to read zero on the scale (Fig. 2). The scale is sensitive to 0.00005 inch per division.

5 . The specimen is then removed from the comparator and gauge blocks are inserted to the nearest 0.001 inch, the difference being read on the scale of the instrument to the nearest 0.0001 inch. This gives a direct comparison to gauge blocks for each length measurement.

6. The specimen then can be exposed to any treatment such as drying, wetting, heating, or the curing eycle of a denture, and the measurement repeated as before.

7. The change in length is computed on the basis of the fiducial reading. The length of the specimen should be corrected for the size of the spheres. Corrections can be made for changes in room temperature, or the specimens can be brought to a constant temperature before measurement.

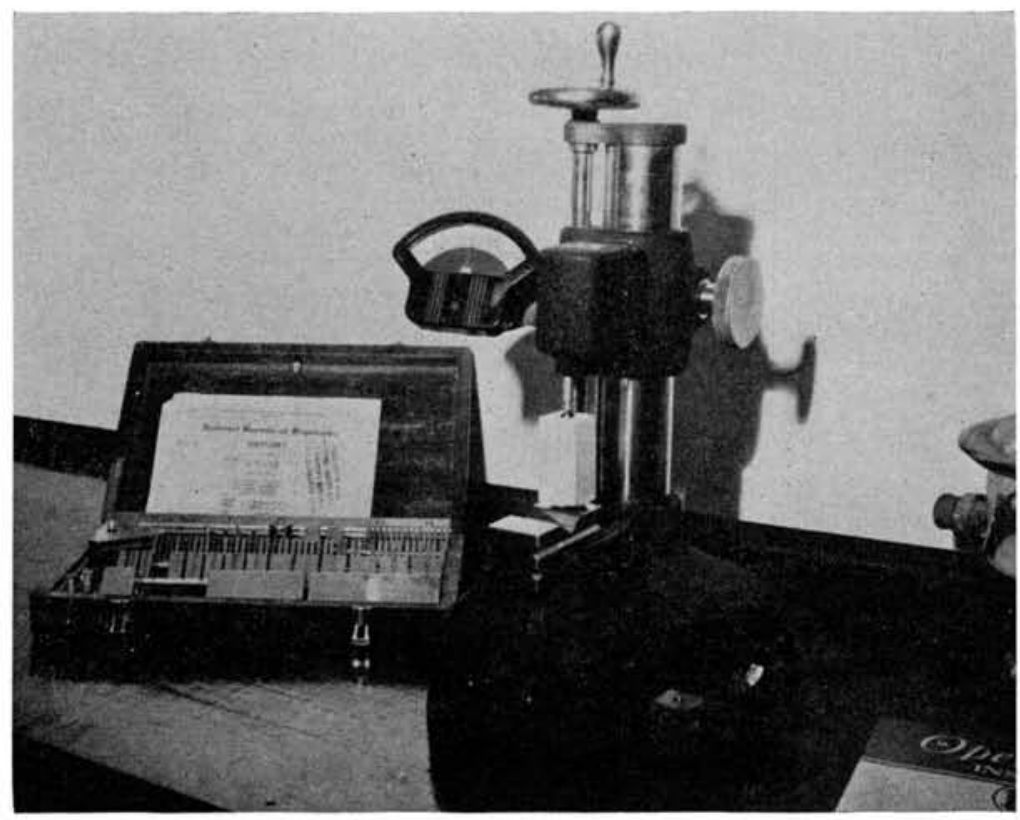

Fig. 2.-Electrolimit Comparator with specimen in position.

\section{APPLICATION OF METHOD}

In order to clarify the use of the above method, the following example (Table I) is given for one specimen, of a series being used in an investigation of the effect of various treatments upon the dimensions of gypsum products. The complete results of this investigation will be reported later. This particular specimen was of $R \& R$ White Castone (Ransom and Randolph) and was subjected to a cyclic treatment involving alternate storage in air (63 per cent relative humidity, $25^{\circ} \mathrm{C}$.) and in water $\left(25^{\circ} \mathrm{C}\right.$. $)$.

The mix was prepared by the standard technic used for dental stones in this investigation. A water powder ratio of $30: 100$ was used. The mix was hand spatulated for 15 seconds, placed in a Kerr Vacuum Investor (Kerr Manu- 
facturing Co., Detroit, Mich.) for 30 seconds, and then vibrated into the mold. Three $3 / 8$ inch and one $7 / 16$ inch steel ball bearings were used on the ends of the specimen. To keep the balls from rotating, a small flat was ground on the embedded side of each.

TABLE I

Example of Data and Calcuration

Material-Castone Specimen No. 13

\begin{tabular}{|c|c|c|c|c|c|c|c|}
\hline \multirow[b]{3}{*}{ STORING CONDITION } & \multicolumn{3}{|c|}{ SPECIMEN * } & \multicolumn{4}{|c|}{ CHANGE IN SPECIMEN } \\
\hline & \multirow{2}{*}{$\begin{array}{c}\text { AGE } \\
\text { (DAYS) }\end{array}$} & \multirow{2}{*}{$\frac{\text { WT. }}{\text { (GM.) }}$} & \multirow{2}{*}{$\frac{\text { LENGTH }}{\text { (IN.) }}$} & \multicolumn{2}{|c|}{ WEIGHT } & \multicolumn{2}{|c|}{ LENGTH } \\
\hline & & & & GM. & $\%$ & IN. & $\%$ \\
\hline $\begin{array}{l}\text { Air, } 63 \% \text { relative } \\
\text { humidity } 25^{\circ} \mathrm{C} .\end{array}$ & 0 & 95.210 & 2.5299 & 0.000 & 0.00 & 0.0000 & 0.000 \\
\hline $\begin{array}{c}\text { Air, } 63 \% \text { relative } \\
\text { humidity } 25^{\circ} \mathrm{C} .\end{array}$ & 4 & 89.020 & 2.5298 & -6.190 & -7.72 & -0.0001 & -0.005 \\
\hline $\begin{array}{l}\text { Air, } 63 \% \text { relative } \\
\text { humidity } 25^{\circ} \mathrm{C} \text {. }\end{array}$ & 6 & 88.615 & 2.5297 & -6.595 & -8.22 & -0.0002 & -0.009 \\
\hline $\begin{array}{l}\text { humidity } 25^{\circ} \mathrm{C} \text {. } \\
\text { Air, } 63 \% \text { relative }\end{array}$ & 8 & 88.605 & 2.5297 & -6.605 & -8.24 & -0.0002 & -0.009 \\
\hline $\begin{array}{l}\text { humidity } 25^{\circ} \mathrm{C} \text {. } \\
\text { Air, } 63 \% \text { relative }\end{array}$ & 10 & 88.610 & 2.5296 & -6.600 & -8.23 & -0.0003 & -0.014 \\
\hline $\begin{array}{l}\text { humidity } 25^{\circ} \mathrm{C} \text {. } \\
\text { Air, } 63 \% \text { relative }\end{array}$ & 11 & 88.615 & 2.5296 & -6.595 & -8.22 & -0.0003 & -0.014 \\
\hline $\begin{array}{l}\text { humidity } 25^{\circ} \mathrm{C} \text {. } \\
\text { Air, } 63 \% \text { relative }\end{array}$ & 14 & 88.570 & 2.5295 & -6.640 & -8.27 & -0.0004 & -0.019 \\
\hline $\begin{array}{l}\text { humidity } 25^{\circ} \mathrm{C} \text {. } \\
\text { Air, } 63 \% \text { relative }\end{array}$ & 21 & 88.575 & 2.5296 & -6.635 & -8.27 & -0.0003 & -0.014 \\
\hline humidity $25^{\circ} \mathrm{C}$. & 28 & 88.610 & 2.5296 & -6.600 & -8.23 & -0.0003 & -0.014 \\
\hline Water, $25^{\circ} \mathrm{C}$. & 32 & 96.350 & 2.5298 & 1.140 & 1.42 & -0.0001 & -0.005 \\
\hline $\begin{array}{l}\text { Water, } 25^{\circ} \mathrm{C} \text {. } \\
\text { Air, } 63 \% \text { relative }\end{array}$ & 36 & 97.005 & 2.5300 & 1.795 & 2.24 & 0.001 & 0.005 \\
\hline $\begin{array}{l}\text { humidity } 25^{\circ} \mathrm{C} . \\
\text { Air, } 63 \% \text { relative }\end{array}$ & 42 & 88.320 & 2.5299 & -6.890 & -8.59 & 0.0000 & 0.000 \\
\hline humidity $25^{\circ} \mathrm{C}$. & 47 & 88.310 & 2.5298 & -6.900 & -8.60 & -0.0001 & -0.005 \\
\hline Water, $25^{\circ} \mathrm{C}$. & 49 & 95.610 & 2.5301 & 0.400 & 0.50 & 0.0002 & 0.009 \\
\hline $\begin{array}{l}\text { Water, } 25^{\circ} \mathrm{C} \text {. } \\
\text { Air, } 63 \% \text { relative }\end{array}$ & 54 & 96.465 & 2.5302 & 1.255 & 1.56 & 0.0003 & 0.014 \\
\hline $\begin{array}{l}\text { humidity } 25^{\circ} \mathrm{C} \text {. } \\
\text { Air, } 63 \% \text { relative }\end{array}$ & 56 & 88.030 & 2.5300 & -7.180 & -8.95 & 0.0001 & 0.005 \\
\hline humidity $25^{\circ} \mathrm{C}$. & 69 & 88.015 & 2.5299 & -7.195 & -8.96 & 0.0000 & 0.000 \\
\hline Water, $25^{\circ} \mathrm{C}$. & 84 & 97.160 & 2.5302 & 1.950 & 2.43 & 0.0003 & 0.014 \\
\hline
\end{tabular}
inches.

Weight of spheres $14.970 \mathrm{Gm}$. One-half diameter of spheres 0.4062 inch.

Net weight of specimen $\left(W_{s}\right) 80.240 \mathrm{Gm}$. Net length of specimen (Ls) 2.1237 inches.

The specimen was allowed to remain in the mold until setting was completed. After removal from the mold, it was placed in a saturated atmosphere for one-half hour to allow it to cool to room temperature. This was necessary because the specimen was heated by the exothermic heat of the setting reaction. All subsequent readings were also made at room temperature (approximately $23^{\circ}$ C.) to obviate thermal changes during measurement. The specimen was weighed to the nearest $5 \mathrm{mg}$. and this value recorded as $W_{o}$ (Table $I$ ). The length of the specimen was measured immediately by the method outlined above and recorded as $L_{0}$.

After these measurements had been made the specimen was stored in a controlled atmosphere approximating summer laboratory conditions (63 per 
cent relative humidity, $25^{\circ} \mathrm{C}$.). At various intervals the specimen was removed and again weighed and measured. After 4 weeks' storage under these conditions, it was immersed in water $\left(25^{\circ} \mathrm{C}\right.$.). This wetting and drying cycle was repeated 3 times. The method used for measuring wet specimens was the same as that for dry ones except that the specimen was removed from the water, wiped with a towel, and weighed immediately.

The first 4 columns of Table I are relatively self-explanatory. They are all known or measured values. The last 4 columns are calculated values derived from the first 4 . The changes in weight and length were found by subtracting the appropriate original value $\left(\mathrm{I}_{0}, \mathrm{~W}_{0}\right)$ from the value at any given time. This gives the total change in grams and inches. In order to compare specimens of slightly different weight and length, these changes were reduced to a percentage basis. To do this, a standard weight equal to the original weight minus the weight of the balls was used as the divisor. Similarly, a standard length equal to the original length minus the radius of each size ball was used to convert to per cent change in length. This length is the distance between the centers of the balls, and is the effective length of the specimen.

TABLE II

Change in Dimensions of Dental Stone and Plaster With Loss in Weight Caused BY DRYING

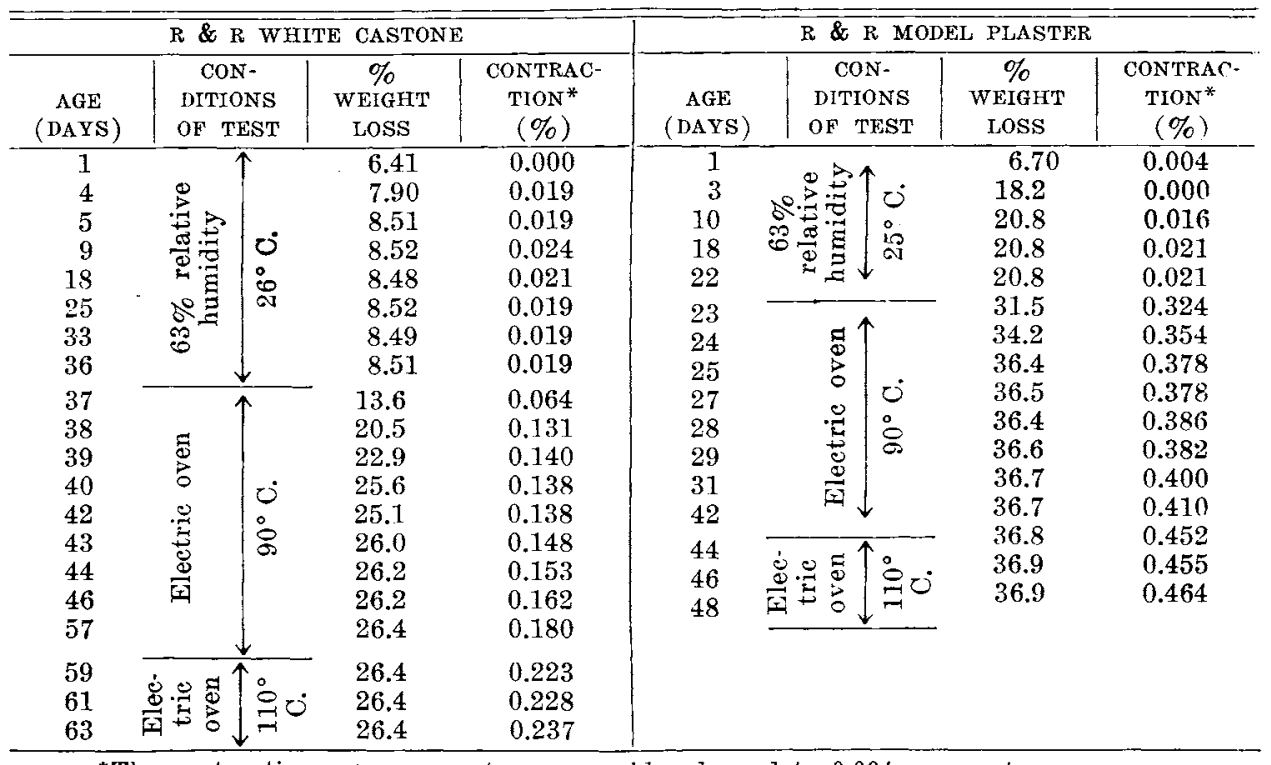

*The contraction measurements are considered good to 0.004 per cent.

Table II is a summary of 4 data sheets such as Table I. It presents the average values for 2 dental stones and for 2 model plaster specimens undergoing a drying treatment. Each pair of specimens is a duplicate which was made the same day and received the same treatment, but each specimen represents a separate mix. The plaster specimens were made with a water powder ratio of $50: 100$, the stone specimens with a ratio of $30: 100$. 


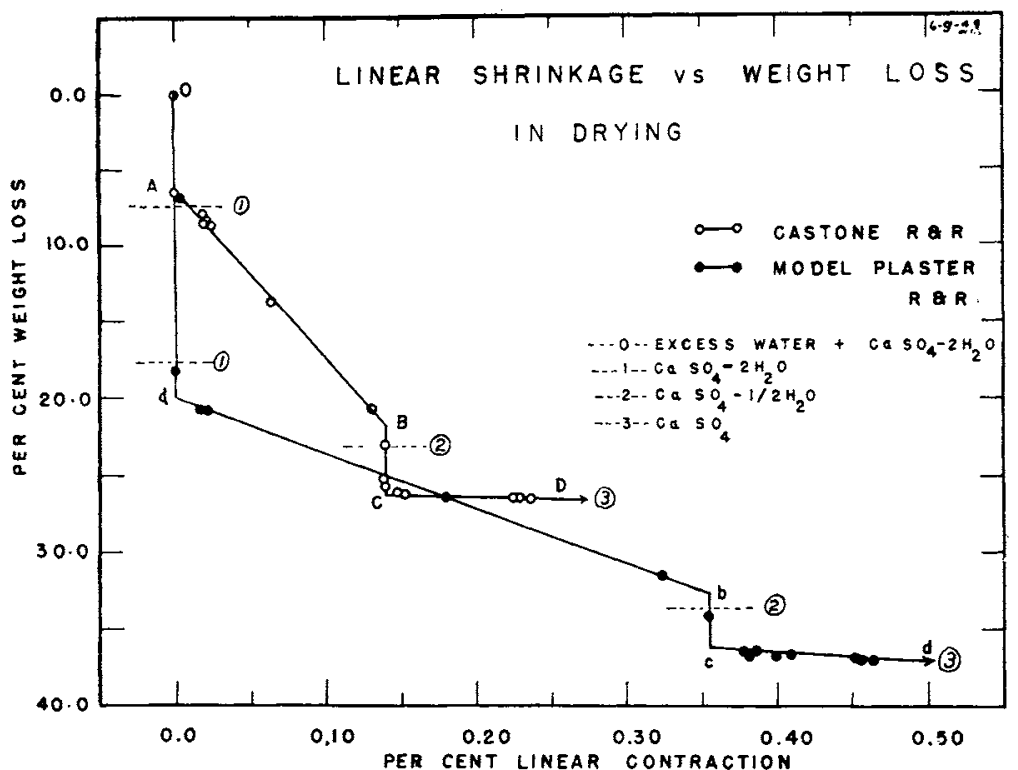

Fig. 3,-Comparison of weight loss and linear contraction of dental stone and model plaster.

\section{LINEAR CONTRACTION VS DRYING TIME}

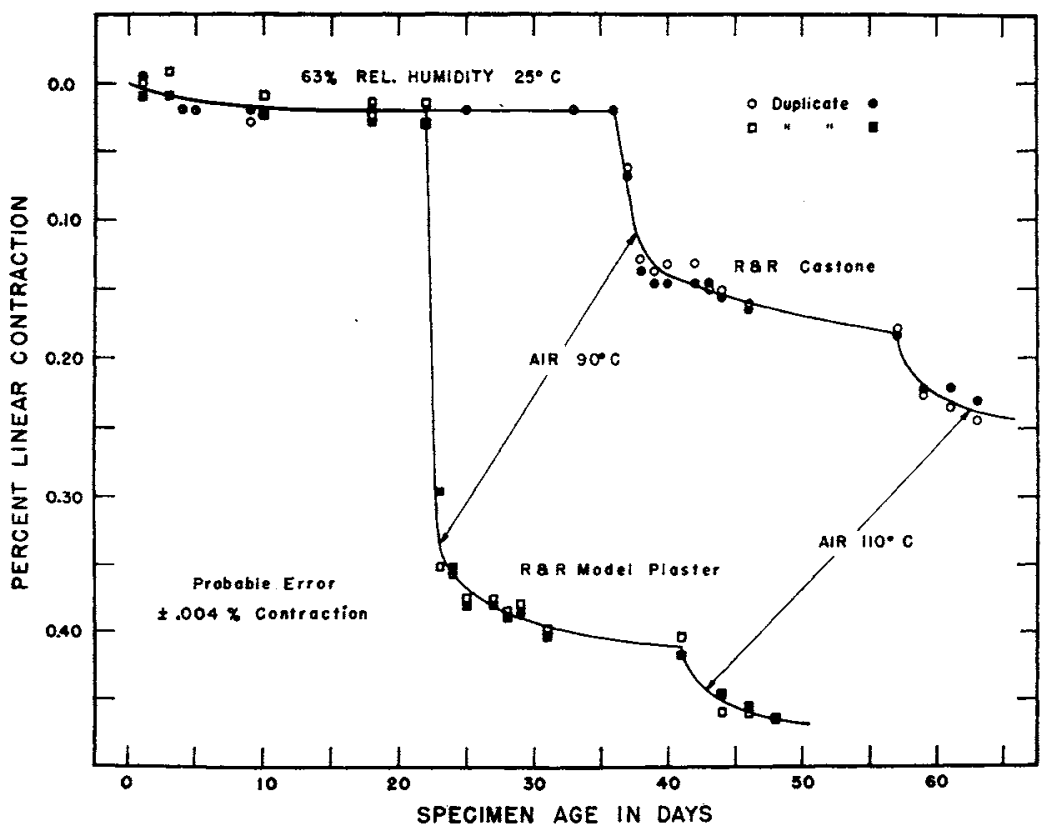

Fig. 4.-Dimensional change in dental stone and model plaster stored at $25^{\circ} \mathrm{C.}, 90^{\circ} \mathrm{C}$., and $110^{\circ} \mathrm{C}$ 


\section{RESULTS}

In Fig. 3 is plotted the per cent weight loss and per cent contraction columns of Table II. It demonstrates the relationship between water loss in drying and the resulting shrinkage, and indicates that it is apparently closely related to the chemistry of the $\mathrm{CaSO}_{4}$.

Knowing the water powder ratio used and assuming that the original powder was composed entirely of $\mathrm{CaSO}_{4} \cdot 1 / 2 \mathrm{H}_{2} \mathrm{O}$ it is possible to compute the weight loss required to remove all excess water and leave $\mathrm{CaSO}_{4} \cdot 2 \mathrm{H}_{2} \mathrm{O}$. This weight loss is indicated as 1 on Fig. 3, and it is apparent that the removal of excess water has no appreciable effect on specimen length. Removal of more water will eventually transform the specimen from $\mathrm{CaSO}_{4} \cdot 2 \mathrm{H}_{2} \mathrm{O}$ to $\mathrm{CaSO}_{4} \cdot 1 / 2 \mathrm{H}_{2} \mathrm{O}$, and the weight loss required to complete this transformation is indicated as 2. It can be seen that this change is accompanied by a marked change in length. Removal of still more water results in a further rapid shrinkage, as $\mathrm{CaSO}_{4} \cdot 1 / 2 \mathrm{H}_{2} \mathrm{O}$ is changed to anhydrous $\mathrm{CaSO}_{4}$, indicated as 3 .

This is of value to the dentist only if he can apply it to the selection of conditions that will prevent undesired dimensional change. In Figure 4 is presented, therefore, a graph of per cent contraction versus drying time for the same specimens, with the storage conditions as a parameter.

From this graph (Fig. 4) it appears that no significant change in dimension occurs as a result of storage of specimens under normal laboratory conditions, but that an increase in storage temperature leads to water loss and shrinkage. The calculated probable error of measurement of the data in Table II is \pm .004 per cent contraction, and \pm .006 per cent weight loss. This means that the measurement errors in each observation fall within the area of the dots used in Figs. 3 and 4, to represent an individual observation.

It should be emphasized that these data are included only as a demonstration that the suggested method of measurement has sufficient sensitivity to measure the dimensional changes that occur in gypsum products under the conditions encountered in dental practice. Until the authors' investigation of the storage properties of gypsum products is completed, they wish to draw no conclusions about them on the basis of the above data alone.

\section{CONCLUSIONS}

The method described provides a means of determining the dimensional changes occurring in gypsum products with great sensitivity. It allows the use of a greater variety of treatments and avoids the failings inherent in previous methods used for this purpose.

\section{REFERENCES}

1. Coleman, R. L.: Physical Properties of Dental Materials. III. Progress Report of Research in Dental Casting Process, D. Cosmos 68: 743, 1926.

2. Taylor, N. O., Paffenbarger, G. C., and Sweeney, W. T.: Dental Inlay Casting Investments; Physical Properties and a Specification, J. A. D. A. 17: 2266, 1930.

3. Worner, H. K.: Dental Plasters, Australia J. Dent. 46: 1-10, 1942.

4. Docking, A. R., and Donnison, J. A.: The Hygroscopic Setting Expansion of Dental Casting Investments, Austrailia J. Dent. 52: $160,1948$.

5. Hidnert, P., and Sweeney, W. T.: Thermal Expansion of Magnesium and Some of Its Alloys, Bureau of Standards $J$. Research 1: 771, 1928. 